\title{
UNRWA and its Role in Lebanon
}

\author{
YVES BESSON
}

Dopartment of Contemporary History. University of Fribourg, Switzerland

Following a historical presentation of UNRWA's mandate, the article examines the major problems currently facing the agency, with a focus on the situation in Lebanon. An outline of the urgent needs among the Palestinian refugee community and of the funding crisis facing the agency is given. The author then discusses the role of this 50 year old institution in the context of the Madrid Conference and the Oslo Agreements, recommends ways in which the international community can support UNRWA in this time of transition and calls for a new framework of cooperation between UNRWA and the Lebanese government.

\section{UNRWA's Mandate}

Following the creation of the State of Israel, the hostilities which immediately broke out and the flight of tens of thousands of Palestinians to neighbouring Arab countries, on 19 November 1948 the UN General Assembly adopted Resolution 212, establishing the United Nations Relief for Palestine Refugees. This organization was designed to plan and implement a relief programme and to scek the aid of UN Specialized Agencies and NGOs such as the ICRC, the League of Red Cross Societies and the American Friends Service Committee.

At that time, it was presumed that the refugee problem would be resolved in a few months. By the summer of 1949 , it had become obvious that some other approach was needed and the UN Economic Survey Mission for the Middle East was despatched to study and report on conditions and make recommendations concerning future assistance for the Palestine refugees. After three months of field research the mission recommended in a report to the General Assembly the creation of a new agency, which would not only carry out relief on a diminishing scale, but would inaugurate a works programme in which able-bodied refugees could become self-supporting, and which would at the same time create works of lasting benefit to the refugees and the countries concerned. On 8 December 1949, the Fourth General Assembly adopted resolution 302 (IV), embodying the recommendation of the Economic Survey Mission and establishing UNRWA.

The new agency became operational in the field in May 1950, assuming responsibilities for over 950,000 refugees (greatly exceeding the Economic Survey Mission's estimate of 750,000). UNRWA's first headquarters was 
established in Beirut. An Advisory Committee consisting of France, Turkey, the United Kingdom and the United States-subsequently augmented to include Egypt, Jordan, Syria, Belgium, Japan and Lebanon-was set up to assist. In 1950, the estimated number of Palestine refugees in 17 countries was $1,491,200$, distributed as shown in Table 1 .

Since 1950, UNRWA's mandate has been repeatedly extended, as a subsidiary organ of the UN and a temporary organization, in the absence of a solution to the Palestine problem, "to carry out direct relief and works and to plan for the time when relief was no longer needed.'

For operational purposes related to eligibility for registration and services, UNRWA has formulated its own working definition of a 'Palestine refugee'. According to this operational definition,

Palestine refugees are persons whose normal place of residence was Palestine during the period 1 June 1946, to 15 May 1948, and who lost both their homes and means of livelihood as a result of the 1948 conflict, and took refuge in one of the countries or areas where UNRWA provides relief, and their descendants.

This operational definition has been brought to the attention of the General Assembly of the UN and other circles in various annual reports of the Commissioner-General of UNRWA and has acquired a certain 'legitimacy' by reason of the length of time it has been in use.

Reading the agency's definition of a Palestine refugee in the light of General Assembly Resolution 194 (111) of 1948, makes it clear that a twofold (albeit substantially overlapping) categorization of refugees is created between:

Table 1

Palestinians in 17 Countries/Areas, Including Host Countries (1950)

\begin{tabular}{lc}
\hline Country/Area & Palestinian Population \\
Gaza Strip & 240,300 \\
Jordan & 122,500 \\
Lebanon & 89,000 \\
Syria & 74,900 \\
West Bank & 764,900 \\
Egypt & 11,600 \\
Iraq & 3,500 \\
Kuwait & 17,000 \\
Libya & 400 \\
Qatar & 300 \\
Saudi Arabia & 2,000 \\
Israel & 160,700 \\
United States of America & 3,300 \\
Total & $1,491,200$ \\
\hline
\end{tabular}

Source: Interim Report of the Director of the United Nations Relief and Works Agency for Palestinc Refugees in the Near East, New York, 1951. 
- Refugees who under Resolution 194 (111) are eligible for repatriation or compensation because they lost their homes or who are eligible for compensation because they suffered loss of, or damage to property, and -Refugees eligible for UNRWA services and assistance.

On June 30, 1995, 3.17 million Palestine refugees were registered with UNRWA.

\section{Palestine Refugees in Lebanon}

In 1951, refugees in Lebanon numbered around 100,000 , while on 30 June 1995, the figure for registered Palestine refugees was 346,164 . This has led to conflicting estimates of local Palestinian population size, distribution, growth rate, migration patterns and other social or economic indications, all made much more uncertain by the dislocation of war. For example, in 1952, the Ministry of Interior estimated the number of Palestinians in Lebanon at 180,000 and in 1968 at 223,000 , while today officials speak of anywhere between 400,000 and 600,000 .

The first two figures are dubious and imply an unrealistic growth rate of under two per cent; the last two are consistent with a four to five per cent growth rate, which is realistic taking into account other rates observed in the region and combines registered and non-registered refugees residing in Lebanon. However, these last figures tend to ignore 50,000-60,000 in estimated casualties and thousands more in outflow from the country since the war years, particularly the 'war of the camps' of 1983-85, when the Amal militia attacked Palestinian refugee camps. Finally, one has to take into account certain nonpublicized figures of those refugees (registered or non-registered) who have been granted Lebanese nationality, especially during the last years. For instance, during the period 1950-72, some 3,000 Palestinian families were given Lebanese citizenship. The influx from Jordan after 1970 is not statistically significant. The inflow from the Gulf after the expulsions from Kuwait is around 450 families (UNRWA estimates), but these persons are most likely returnees and thus do not affect existing totals. In raw demographic terms, inflow is offset by casualties and by outflow since 1987, both known and undetermined. Thus, it is not likely that the overall population is significantly larger than the current UNRWA tally of 346,164 (June 1995) registered refugees. Moreover, if the UNRWA estimated growth rate of 3 per cent (among registered refugees) is any indication, Lebanon's Palestinian community has undergone a net decline, not increase, over the past 20 years. Finally, in addition to the registered refugees, non-registered refugees in Lebanon were estimated in 1993 at 38,000 persons.

This demographic aspect is obviously at the heart of the Palestine refugee problem. The Madrid Conference (1991) and then the Oslo Agreements (1993) stimulated research on the demography of the refugees, not to mention multiple declarations and political positioning. Throughout its participation in 
the multilateral peace process, UNRWA has always defended its official position-that the statistics and figures it publishes concerning the many aspects of the 1948 refugee situation are of purely operational value and intended primarily to serve the optimal quality of the services it provides, in view of its budget. The fact that the agency's statistics are so often used and referred to tends to reveal, however, the absence of reliable data other than those established by UNRWA. Frequent criticism of demographic data published by the agency therefore seems to have chosen the wrong target or. perhaps, conceals political objectives. UNRWA does not have a mandate as a civil authority for registration of population fluctuation; its statistics are for its own management and operational needs. Unfortunately it is all too often forgotten that only by keeping strictly to its mandate has the agency been able to fulfil this mandate for nearly half a century. As far as criticism of its demographic statistics in particular is concerned, this stems mainly from sources which are even less well-equipped to provide reasonably credible data.

\section{The Present Situation}

Palestine refugees registered with UNRWA represent 10-12 per cent of the Lebanese population and 47 per cent live in 12 refugee camps. There is no doubt that the situation today for Palestine refugees in Lebanon is particularly difficult. Over the past few years since the end of the civil war, their socioeconomic situation has deteriorated, a unique phenomenon in the region. The cycle of violence during the 15 years of civil war seriously affected the refugees, and resulted in thousands of them being displaced inside the country, while a large population which had left the camps before 1975 returned to live in already congested conditions.

Palestinians in Lebanon are prohibited by law from practising most professions, including law, medicine, pharmacy, and engineering. The camps are densely populated, have scant economic resources, low per capita income. and very few formal employment opportunities. Only a few individuals are able to obtain a work permit which, even then, offers neither social security, insurance benefits, nor a regular wage increase. Palestinians may not work without special permits, and very few have been able to find regular employment because they are treated as other foreign residents. This situation is well known and, although the subject is dealt with in other papers presented here, it is worth mentioning that it represents a heavy burden for UNRWA. In fact, around 11 per cent of the UNRWA-registered Palestinian population is registered as Special Hardship Cases (SHC)-refugee families unable to sustain themselves. This programme grants direct relief assistance to families without an able-bodied male adult. In Lebanon this proportion is double the average of the other UNRWA fields of operations. It spotlights the extremely difficult situation of the refugee community in Lebanon where, compared to other countries in the region hosting Palestine refugees, the rate of unemployment is very high (around 40 per cent). This is the result of the drop in employment 
opportunities in the Arabian peninsula since the Gulf War, the large numbers of Syrian workers who compete with the refugees, the halting recovery of the economy, the troubles in the south and a high inflation rate.

During the past few years, in addition to the education, health and social services it provides free, the agency has had to address the following urgent needs as specific to the situation of the refugees in Lebanon. First, a very high percentage of the poorest of the poor (11 per cent registered as Special Hardship Cases). In particular, the conditions of several thousand shelters belonging to families registered as SHC are below acceptable standards of hygiene, construction and size and are in need of rehabilitation. Secondly, the agency has had to address hospitalization. Here, the refugees' situation is also unique compared to the other countries where the agency operates. In addition to the fact that they do not have access to government health and social institutions, they do not benefit from public hospitals or other social services. Basically, they are entirely dependent on UNRWA health services. Years ago they could use the services provided by the Palestine Red Crescent, but those services have now been reduced and in some places have come to a halt. Today the agency alone is unable to meet all hospitalization needs as it should. The growth of the population, its pauperization and the considerable increase in prices in the hospitals with which UNRWA contracts (a 50 per cent increase between 1994 and 1995, for example) have added to the problem. Moreover, the agency does not offer full hospitalization coverage for expensive treatment. The refugees are thus obliged to pay the balance, which is far beyond their means in most cases.

According to WHO norms, the ratio of hospital beds to the population should be a minimum of 2 per 1,000 persons. In Lebanon the subsidized number of beds which the agency can afford is far more scarce, at 0.25 per 1,000. Priorities have to be established for emergencies and life-saving cases, while waiting lists become longer and longer.

Table 2 shows the dramatic decrease in the offer of beds in recent years and illustrates the worsening of the refugees' public health situation. Lack of resources and budgetary constraints, accrued interest, and the international community's focus on the Occupied Territories after Madrid and Oslo are the main causes of this trend.

The third urgent need relates to displaced refugees. The war in Lebanon which started in 1975 resulted in thousands of Palestinians killed, injured, missing, disabled or displaced. More than 6,000 refugee families were displaced. Up to the end of 1995 , the agency could only help by rehousing about 600 families inside existing camps. As an example, in 1996 there were still 15,000 individuals (3,230 families) squatting in Beirut and Saîda. The agency has worked closely with the Government to find solutions for displaced refugee families who were occupying Lebanese buildings and had received eviction notices.

This question of relocation of Palestine refugees takes on particular political importance in Lebanon. Certain property development projects aiming to 
Table 2

Avallability of Hosptial Beds for the Refugee Population 1989-1995

\begin{tabular}{lcccc}
\hline Year & Population & $\begin{array}{c}\text { Budget in US } \\
\text { Smillions }\end{array}$ & No. of Beds/day & $\begin{array}{c}\text { Beds/1000 } \\
\text { population }\end{array}$ \\
\hline 1989 & 256,000 & 2.42 & 144 & 0.56 \\
1990 & 261,000 & 2.15 & 144 & 0.55 \\
1991 & 268,000 & 2.14 & 130 & 0.48 \\
1992 & 319,000 & 1.87 & 109 & 0.34 \\
1993 & 332,000 & 1.69 & 108 & 0.29 \\
1994 & 342,000 & 1.72 & 96 & 0.28 \\
1995 & 346,164 & 1.72 & 85 & 0.25 \\
\hline
\end{tabular}

rehouse refugees from Beirut far from the capital stirred up political storms because they touched on the central question of the Palestinian presence in the country. This led to the Lebanese Government's ban on the agency's activities to build new shelters or even new premises in certain areas. Only rehabilitation of existing shelters or buildings, within the boundaries of the camps, was allowed as of 1996.

Fourth is the question of infrastructure. The authorities themselves are facing difficulties in meeting the needs of the population in this sector of reconstruction and their plans did not include the 12 Palestinian camps where 170,000 refugees are living. There is no adequate provision of drinking water, either in quantity or quality. Only five per cent of shelters are coninected to state networks and most of the water-supply pipes are laid along sewage drains, increasing considerably the risks of water contamination. Sewage networks are totally inappropriate and vast areas in the camps still rely on open drains. Individual private pits and latrines are commonly discharged or overflow into open drains, roads and pathways. All access roads into and within camps are in deplorable condition.

Improvement of the environmental health conditions inside the camps should go along with the general health policy applied by the authorities in the municipalities and villages in order to prevent health hazards. In this sector projects have been cleared with the government, which wishes to see that the level of pollution is reduced in the camps as well, in line with its environmental health policy.

The fifth urgent need is education. UNRWA's education programme runs 75 schools with an enrolment of 35,000 pupils and students; it operates one vocational training centre, offering 19 different courses to 635 students, and provides $\mathbf{4 0}$ university scholarships with only partial coverage of tuition fees. Over recent years, this programme has faced serious problems of double shifts and overcrowding, lack of up-to-date teaching facilities, inadequate physical facilities, and freezing of training places at vocational installations. 
The fact that Palestinians are deprived of most civil rights has resulted in chronic education problems. Their access to public schools (run by the government) is restricted. The exorbitant private school tuition fees at all levels cannot be met by most of them. There is a rush of new pupils to UNRWA schools as the only alternative for enrolment, particularly to those schools which have achieved a good reputation. For these reasons, the agency is facing an urgent need for new educational premises to accommodate the increasing demand on its schools.

\section{UNRWA's Future}

\section{In the Middle East}

With the Madrid Conference in 1991, but above all following the Oslo -Agreements in 1993, it has become obvious that, as a temporary organization whose mandate is regularly renewed by the General Assembly, UNRWA is destined to disappear gradually as the peace process progresses. Once this has been established, all that remains is the conceptualization of UNRWA's optimal role during the long intermediate period, bearing in mind the progress and setbacks already seen.

For more than 45 years of existence, the agency has organized its programmes and operations in a more or less uniform way in its five fields of operation: Lebanon, Jordan, Syria, the West Bank and Gaza. Over the years its structures have settled into place and its management procedure and programme initiatives were in fact all very similar from field to field, centred around a headquarters first in Beirut, then in Vienna and now in Gaza, even when circumstances and needs often meant that the agency had to organize more specific operations in one particular field. This is how educational methods, health and social services developed in such a way that they resulted in a sort of Palestinian-UNRWA 'pattern'. In other words, for fifty years, in all the main aspects of life, education, health and social solidarity, a genuine UNRWA 'culture' developed. Here the international public service spirit, often influenced by the different nationalities of expatriate personnel and Palestinian attitudes, blended together to produce this UNRWA 'culture'. Of course this 'culture' offers different facets according to the particular field of operations concerned, influenced among other things by the predominant political regimes. But, as a general rule, each of the 20,000 agency employees could easily be transferred from one field to another without meeting serious professional integration problems. This means that for several generations of Palestinians, UNRWA has represented one of the few possibilities open to them for a civil career.

In consequence, when the Palestinian Authority was gradually installed in Gaza and the West Bank, transforming resistance activities into daily management tasks, it was extremely interesting to observe the birth of a legitimate, recognized Palestinian administration working alongside the 
smoothly-run, structured, bureaucratic, long-standing, and hence experienced UNRWA networks. For the first time, high-ranking Palestinian executive UNRWA staff members have had to deal with quasi-governmental counterparts who are also Palestinians and legitimate nationally and internationally. This coexistence and co-operation was not at all easy in practice, and is not necessarily trouble-free in principle either, because two legitimacies are brought into play, two heritages, two types of administration: one resulting from international desire not to abandon this refugee population to its fate, and the other stemming from this very community itself with its determination not to remain just a refugee people, and to assert itself on the international scene.

This is obviously a turning-point for UNRWA, not only because it heralds UNRWA's disappearance, but also because the Palestinian people now have an autonomous authority, legitimized by elections. To illustrate this transition, the Palestinian flag is to replace the United Nations flag which had compensated for the absence of the former for so long. When the agency deals with the Palestinian Authority administration in Gaza and West Bank, its counterparts are now the legitimate representatives of the very population it was created to serve.

Thus, UNRWA's position and role in Gaza and the West Bank have been radically transformed. Different changes in its role are likely to take place in Jordan, where refugees have Jordanian nationality in a country now at peace with Israel; in Syria, where UNRWA's activity is very closely controlled by the authorities but where the proportion of refugees within the population is the smallest; and in Lebanon, where the fact that 10-12 per cent of the total population are refugees has always been a problem politically and socially. While UNRWA could manage its five fields in a relatively uniform way so long as the political situation in the Middle East remained blocked, the peace process has set in motion an evolution which will probably lead to increasing differences in the agency's management and policy, both from necessity and as a result of the diverging fates reserved for the various refugee communities by their host states.

In other words, the end of Arabism, the end of the Arab consensus. and separate peace agreements-signed or yet to be signed-are fragmenting the fate of Palestine refugees and will continue to do so, forcing UNRWA to adjust its policy, management and programmes accordingly. This trend towards fragmentation will of course depend on the development of the peace process, but events over recent years have revealed its predominance.

Under these conditions, UNRWA must obviously prepare itself to gradually decentralize the definition and management of its programmes according to requirements which will become increasingly diverse, both socially and politically. UNRWA might undergo an in-depth transformation in some fields, while remaining relatively unchanged in others, or even withdrawing entirely from some fields and continuing its activity in others. In fact, this decentralization-administrative, managerial and probably political-was forced to begin as early as 1978, when UNRWA had to move its headquarters 
from Beirut to Vienna. It remained quite limited and not very political ("political' here refers to the decision-making power in matters regarding the implementation of the agency's mandate, which up to now has been reserved to the Commissioner-General).

After UNRWA's move from Vienna to establish the CommissionerGeneral's Office in Gaza-in the opinion of the writer a premature and risky decision-the decentralization has to be urgently thought out, prepared and planned in the form of flexible scenarios which can be adapted to the changing situation. This time, however, it is not just a question of logistical changes, as was the case in the move from Beirut to Vienna, but also political change. If the agency itself does not give the problem adequate thought, it runs the risk either of having decisions it does not agree with imposed by circumstances, or of seeing other authorities taking inadequate decisions in its place, as has been the case for the move from Vienna to Gaza. Was it really advisable, at this stage in the development of Palestinian autonomy, to relocate agency headquarters to a place where state sovereignty is still very ambiguous? On the one hand, this creates fundamental problems for an international organization, and on the other, because of the political divisions among the various refugee communities today, UNRWA could well be put in an awkward position and even perhaps partially cut off from the population it is there to serve in the different fields.

In the current circumstances, UNRWA needs to adapt its operations to the dynamics of fragmentation which underlie the Arab world and have long been evident. Revealed more sharply by the 1991 Gulf war, this phenomenon has been further accentuated by the peace process. The Palestinian question, for so long both the rationale of pan-Arab unity and its cement, has gradually ceased to play this role since the $1967 \mathrm{war}$, but this function has been explicitly denied in the very structures of the Madrid process and the Oslo Agreements. The focus, first political and subsequently economic, on Gaza and the West Bank, which was necessary for the emergence of a progressively legitimate and rccognized Palestinian entity, inevitably has severe consequences for the refugee diaspora in neighbouring states.

Over the years, social differentiation has emerged among the refugees in Lebanon, Syria, Jordan and even in Kuwait, and has tended to intensify with the end of pan-Arab unity on the question of Palestine. The 'dis-Arabization' of the Palestinian cause, and its growing 'Palestinization' following the intifada and the peace process, obliged UNRWA to re-examine its response to the refugees' increasingly diversified needs. Although socially these needs remain basically similar in, for example, the camps in Jordan, Syria or Lebanon, one cannot completely isolate the response to the social needs of a given population from their political context. The refugees' needs and hence UNRWA's operational requirements are fragmenting: increasingly they diverge not only along a social but also a political line which tends to follow state and regime boundaries. There are significant and deepening differences between the attitudes and policies adopted by the region's various host countries, faced with the prospect of peace, regarding the refugees present on their territory and their 
future. The differing host state policies will have an effect on their respective positions on the refugees and on their demands on UNRWA. In this respect the move of UNRWA Headquarters to Gaza highlighted how views differ in the various host countries and how those views reflect possible future strategies in dealing with both the agency and the refugees it is there to assist.

Both the Madrid process and the Oslo Agreements are intended to address the refugee question: the first uses a multilateral approach (the Multilateral Working Group on Refugees), in operation since 1992, in which UNRWA has participated since the second meeting in Ottawa in 1992; the second intends to address the question on the basis of bilateral regional participation of the parties concerned. According to the agreements already concluded, these two approaches should pursue or commence their work during the interim period, parallel with the other major negotiations which are to accompany the discussions leading up to the elaboration of a definitive status for the Occupied Territories. For the time being, apparently, the results of the Israeli elections of 1996 have cast doubts over the time-table.

However, the positions taken by Israel since Madrid and Oslo, and those taken by Jordan in its peace treaty with Israel (Article 8), both imply that the refugee question might be dealt with separately, according to the interests of each host country, apart from the general principles which will be defended by the Palestinians (Resolution 194) with the support of the different Arab parties, at least as far as practical solutions and their implementation are concerned. As is often the case in such situations, implementation of the policy adopted by a particular host country may well be set in motion before the end of negotiations on the principles, the latter often depending on the former!

In this new and uncertain context, it seems clear that UNRWA will have to adapt its present monolithic organizational structure and prepare to adjust to whichever direction each host country chooses to follow. UNRWA's future during this interim period will no doubt be different in the Autonomous Territories, Jordan, Syria and Lebanon. The most difficult problems for state authorities will probably arise in Lebanon and therefore prospects for the refugees in Lebanon are the least clear. Consequently, this is where the agency will have to give most thought to the refugee situation.

\section{In Lebanon}

In general, the Lebanese authorities have co-operated closely with the agency since 1950-less from a desire to intervene in its activities than from concern to safeguard their political position regarding the refugee question and to avoid integration of the refugees in Lebanese society. The relationship UNRWA has had with the Lebanese authorities has always been quite different from that it has had with other governments. Certain of the pre-civil war regime's liberal and democratic characteristics resulted in weaknesses within successive governments and exposed UNRWA to rougher political storms than elsewhere in the region. This explains why, in Lebanon much more than anywhere else, 
the agency was obliged to assume, and sometimes endure, the political consequences of its mandate and of its very existence. It has also had to live through difficult circumstances during periods of open conflict. UNRWA is the only UN organ never to have left Lebanese soil since 1950 and has never ceased its operations. It often had to accept compromises to safeguard its security, a minimum of immunity and, above all, the pursuit of its services to the refugees. This was particularly the case when Palestinian organizations ruled the camps. As an organization created for the Palestine refugees and employing mainly Palestinians to carry out its operations, under the leadership of a few international staff members, there was a delicate demarcation between the ambitions and national cause of its clients and the majority of its employees, its status as a UN international organization, and the interests of the host country as they were defined and defended by the government of that time in the agitated interplay of Lebanese politics. This was all the more so because, more often than not, Lebanon was both the mirror-image and the battlefield for the major Arab rivalries and ambitions. On the one hand, UNRWA was perceived by the host governments as the materialization and recognition of the international character of the Palestinian problem, its duration and the absence of a solution. On the other hand, the agency was taken for granted by its clientele both as minimum compensation for their suffering, as the very symbol of the 'provisional', makeshift living conditions they were forced to settle down in, and also as a support and social authority substitute in the absence of their own national civil authority. In its daily activities, UNRWA therefore experienced all the facets of Arab political life and its engulfing ideological surges.

Considered by the Palestinians as a Palestinian organization, by the Arab countries as a source of financing for host governments in the service of the Arab cause, and by the international community, which finances it, as an international humanitarian organization-and therefore neutral and apolitical by definition and mandate-UNRWA has had to face the most delicate political situations in order to be able to pursue its operations. While the limits were always clearly marked out in the Occupied Territories, the situation in Lebanon has always been more fluid and more volatile because of the very characteristics of the Lebanese political arena. All the actors in the Lebanese political game have in turn considered the presence of the Palestine refugees as a foreign, destabilizing element, while they never hesitated to join forces temporarily or locally with the Palestinian factor so long as it was useful to them in unsettled circumstances.

Throughout the long stalemate in the Middle East conflict and the Palestinian question, UNRWA has made a perfect scapegoat on which refugees and authorities or the community structures could freely vent their frustrations. The agency has often had to be the buffer, an outlet for feelings of anger and frustration on all sides-shouldering the whole blame, locally, for the inadequacies, shortfalls or lack of interest of the international community. In addition, UNRWA has struggled to maintain a neutral position in the 
power struggles which have beset Lebanon, in order to maintain the assistance provision required by its mandate.

Today, out of the total of 20,600 jobs in the Middle East in the spheres of health, education and social services, UNRWA employs 2,500 people in Lebanon, fewer than 10 of whom are non-Palestinians. The agency operates 75 schools for 35,200 pupils and the Siblin Training Centre provides vocational and technical instruction to 635 trainees, of whom 113 are women. Health services are delivered through an expanded network of 25 health centres and hospital care is provided through contractual arrangements with 11 general hospitals and two mental hospitals. Social services run housing programmes, poverty alleviation programmes, income-generation programmes, communitybased rehabilitation and integration programmes.

The main problem for the Palestinian community in Lebanon now is that the Madrid and Oslo agreements have not really opened up prospects of a solution nor brought any tangible improvements in everyday life. They are therefore perceived negatively because by defining the stakes as it does, the peace process is considered by the disillusioned majority of refugees as a dead end for their own destiny or, worse, as a betrayal of the traditional Palestinian political position since 1948.

What is more, the international community's efforts in favour of the Territories and Palestinian autonomy, and consequently UNRWA's financial difficulties, sent a negative signal about the peace process to the refugee community. Rightly or wrongly, refugees in Lebanon felt an immense sense of abandonment and neglect. Immediately after the Oslo agreements in 1993, UNRWA warned the international community about the necessity of not forgetting the refugees and the Palestinians of the refugee diaspora, otherwise these communities would turn away from peace. These circumstances and UNRWA's financial difficulties prevented the agency from dealing with the increasing needs in Lebanon, and this no doubt helped to worsen their feeling that they were abandoned. In New York, before the different UN bodies, as well as at sessions of the Multilateral Working Group on Refugees (MWGR) the Commissioner-General of the agency or his representative constantly stressed the urgency and the necessity for the international community to make an effort in favour of the refugees, parallel to efforts being made for the Territories and Palestinian autonomy. In fact, UNRWA representatives constantly emphasized in their declarations the absolute necessity of backing up the hope of a political solution resulting from the Oslo Agreements for the Palestinians of the Territories, by a parallel material effort to relieve the refugees' difficulties elsewhere in the Middle East and thus help them live through the interim period while a definitive solution to their problem is worked out.

There remains a flagrant imbalance between aid provision for the Palestinian Authority areas and for refugees in the host countries, in spite of contributions and projects financed by members of the MWGR in Jordan, Syria and Lebanon. It is particularly regrettable that since the signature of the Oslo 
Agreements UNRWA's regular budget (covering its recurring costs) has had a growing deficit, which will probably exceed $\$ 30$ million for 1996 . Even if this concentration on funding projects in the West Bank and Gaza Strip is easy to explain, it nevertheless remains extremely dangerous at the political level. Refugee crises have become more and more frequent all over the world and there is, no doubt, a certain donor fatigue. As long as Syria and Lebanon do not come to an agreement with Israel, it is difficult to tackle the issue of refugees. Since 1992, the activities of the MWGR have shown that the refugee question is not only linked with regional peace but, if only by reason of its humane and demographical importance, it is at the heart of the problem beciuse the 1948 catastrophe is omnipresent in Palestinian identity and political outlook.

Today, from all the studies, discussions and contacts undertaken since Madrid, and especially since Oslo, to find solutions to the refugee problem, it appears that Lebanon is a special case. If, within the framework of an agreement on the principles which would satisfy the parties concerned, one considers the practical solutions and settlements host country by host country, and defines the technicalities of a solution, it emerges that a solution for the Lebanese situation would require the most imagination and compromise, and probably a concomitantly greater financial effort. It is paradoxical to suggest that a joint effort on the refugee question, particularly for Lebanon, should be asked of the Arab countries at the very moment when the concept of separate peace agreements in the Middle East (albeit in a global framework), seems to have become the accepted rule. The weakening and fragmentation of the Arab world will not facilitate the working out of a solution for the refugees, above all in Lebanon. The bilateral-pluralist approach which characterizes the Madrid process still has to prove it is useful and effective on the refugee question.

Should a solution eventually emerge, however, the international community and the parties concerned would do well not to forget that, in Lebanon and in the Middle East, they have in UNRWA the existing infrastructure of an agency trusted by all concerned, with the capacity to facilitate and implement solutions on the ground.

\section{Conclusion: A New Framework of Co-operation}

Even if there is very little room to manoeuvre in this interim period, it is in the Lebanese authorities' interests to collaborate closely with UNRWA and fucilitate the delivery of its services. The problem today is that UNRWA needs a new specific politico-legal framework in Lebanon which would be better adjusted to the realities of the Palestinians' presence in the country.

UNRWA operates in its five fields according to different politico-legal frameworks which have influenced its relations with the host countries. After 1950, the agency drew up agreements with the host countries in order to implement its mandate, and then developed relations in the long term which also helped create a politico-legal framework for its operations. In the case of 
Lebanon, this framework was particularly important because from 1950-1978 the agency's headquarters was in Beirut. Generally speaking, the legal aspects of the relationship linking UNRWA to Lebanon have not been adjusted to correspond to the political development of the country, either as regards the events which have shaken the Lebanese state since 1975, or concerning the agency's actual role and the changes on the interior or exterior Palestinian scene or in the Arab world in general.

Over recent years, relations between UNRWA and the restored Lebanese state have been variable, both in the public sphere and at various levels in contacts with governmental and administrative bodies. These incidents or misunderstandings, albeit inevitable considering the sensitivity of the Palestinian problem in Lebanon, might have prompted an agency initiative for a comprehensive update of these relations, reviewing both the framework principles for its operations and UNRWA's actual activities. In the opinion of many, such an update would facilitate the solution of certain existing problems without prejudice to a long-tem redefinition of the agency's presence which would be better adapted to present needs and the new political context.

Without being too hasty in anticipating future political developments, the establishment of a more structured and sustained dialogue between UNRWA and the Lebanese authorities, covering a broader range of issues, would enable the agency to dissipate misunderstandings sometimes created and aggravated by its routine-oriented, day-to-day management. More regular contacts at a higher level would also enable the Lebanese government to explain to the international community as well as the Lebanese public its attitudes to UNRWA's activities and the agency's future, should there emerge a settlement of the refugee question.

Deepening and re-adjusting the relationship between UNRWA and the Lebanese government would also facilitate the development of more diversified and appropriate policies in each host country: If, as seems likely, the peace process leads to different practical solutions of the refugee question for each host country, once the main governing principles of such solutions are established and agreed upon by all parties involved, a relationship of greater trust and cooperation between UNRWA and the Lebanese state can only benefit the refugees.

All data and information included in this paper has been drawn from official public UNRWA documents and from the author's personal experience as Director of UNRWA Operations in the West Bank (1990-92) and as Special Adviser to the Commissioner-General (1993-95). Relevant information on UNRWA's operations in the Near East can be obtained from the Public Information Office, UNRWA HQ, now in Gaza, or in the Commissioner-General's Annual Report to the UN General Assembly published by the UN in New York. 